\title{
The choice of inequality measure in empirical research on distributive judgments*
}

\author{
André Decoster and Erik Schokkaert ${ }^{\dagger}$ \\ (Centre for Economic Studies, KULeuven)
}

June 2000

\begin{abstract}
We analyse questionnaire data from a representative sample of the Flemish working population. For 781 respondents we construct their perception of the actual and of the fair income distribution. We check whether the use of different inequality measures leads to different interpretations of these data. The ranking of individuals on the basis of their perceived and fair inequality is hardly affected and the same is true for the explanation of the interindividual variation. However, the simple classification of individual respondents in those who want and those who do not want less inequality does depend on the measure used in $20 \%$ of the cases. Moreover, the tendency to equalise is a poor measure of conservatism.
\end{abstract}

\section{Introduction}

An important component in the policy debate is the attitude of different social groups towards income distribution and redistribution. Participants in this debate often refer to the degree of income inequality as if this "degree of inequality" were an objective concept. This is of course far from true. What is an "equal"

*This paper forms part of the research programme of the TMR Network Living Standards, Inequality and Taxation [Contract No. ERBFMRXCT 980248] of the European Communities whose financial support is gratefully acknowledged.

†Naamsestraat 69, B-3000 Leuven, Belgium. Email: andré.decoster@econ.kuleuven.ac.be; erik.schokkaert@econ.kuleuven.ac.be 
distribution is clear enough: but the objectivity disappears as soon as we want to rank "unequal" distributions with respect to their degree of inequality. The choice of a specific inequality measure determines what information from the overall distribution will be lost (and what other parts of information will be used) and, more specifically, how much weight is given to the information about the incomes attached to different positions.

Consider two politically relevant questions for empirical research. First, how do people perceive the inequality in the income distribution? Do different social groups have different perceptions? It is obvious that an inequality measure must be chosen before we can rank individuals according to their perception of inequality. There is no a priori reason to think that different measures will yield the same rankings of individuals. Nor is it clear that the explanation of the "degree of perceived inequality" will be independent of the measure used. Second, do people want a decrease in inequality? Or do they perceive a change in the degree of actual inequality? Here the measurement problem is still more important. It is possible that the same desired or perceived shift in the income distribution is a "reduction" in inequality for one measure but an "increase" in inequality for another. The most obvious case is the distinction between "rightist" and "leftist" measures (Kolm, 1976). When asked whether they feel that "inequality has increased during the last decades", two respondents who in fact have exactly the same subjective perception of the changes in the income distribution may nevertheless give a different answer if one (implicitly) uses a scale invariant measure and the other is concerned with absolute distances.

Given this background, it is surprising that much empirical research on people's opinions approaches the problem of inequality measurement in a relatively frivolous and ad hoc way. Popular but simple Gallup poll-questions of the kind: "Do you want more or less inequality in the income distribution?" are ambiguous and hard to interpret if the respondents start from different ethical assumptions and therefore implicitly use different inequality measures. All this implies that one should be careful with sweeping statements about the popular desire to increase or reduce the inequality of the income distribution. It is even possible that some apparent inconsistencies are not inconsistencies after all, but follow from the implicit use of different inequality measures by different people, or, at least as importantly, by the researcher and the respondents.

The ambition of this paper is limited. We want to check whether the relative neglect of the measurement issue in survey research can be justified. We do this by analyzing traditional questionnaire data with an extensive set of inequality 
measures and by looking for possible interpretational differences. Our approach is less ambitious than the one of the recent questionnaire literature on inequality measurement (Amiel and Cowell, 1999, Ballano and Ruiz-Castillo, 1993, Harrison and Seidl, 1994a, 1994b). These authors formulate carefully designed questions about hypothetical distributions in a mythical Alfaland and then check explicitly whether the axioms of economic theory are accepted by lay people. The big advantage of such a well-structured approach is that one stays in touch with theory. However, a potential problem may be that respondents treat these abstract questions rather as an "arithmetical" problem and that they are eager to give a "satisfactory" answer even if they do not have any strong intuitions. This problem is the more serious because almost all this research works with students samples. Moreover, although the researchers usually are extremely careful in emphasizing that the comparisons between the two income distributions have to be interpreted ceteris paribus, we know from psychological research that there is a real danger that respondents do not follow this instruction and implicitly ascribe differences in personal characteristics (such as effort level or productivity) on the basis of income differences. Our questionnaire is less structured but at the same time closer to social reality. In our case the questions can definitely not be interpreted as ceteris paribus. It is therefore much more difficult to derive clear-cut theoretical conclusions. On the other hand, our results are immediately relevant for the social debate. The questionnaire is understandable and interesting for a non-students sample. In fact, our data have been collected from a representative sample of the Flemish working population. We would argue that our approach is complementary to the more theoretically oriented work: both try to bridge the gap between economic theorizing and people's opinions, but both come from opposite sides.

We present our data in section 2 . In section 3 we try to see whether it is possible to derive from these data more specific information on the inequality measure used implicitly by the respondents. Section 4 investigates whether the use of different inequality measures leads to different conclusions about the interindividual variation in the perception and evaluation of the inequality in the overall distribution. Section 5 raises some related questions concerning the classification of respondents as redistributors or non-redistributors and section 6 discusses the relationship between conservatism and the tendency to equalise the income distribution. It will turn out that the choice of inequality measure is not fully innocuous. Section 7 concludes. 


\section{A first description of the data}

Our empirical work is based on the results of interviews on justice opinions carried out with a representative sample of 810 respondents from the Flemish working population in October-November 1988. In this paper we only use the first part of the questionnaire centering on the perception and evaluation of the aggregate income distribution. The respondents answered this part before they were confronted with explicit questions on the ethical justification of income differences and on economic policy. Missing values have reduced the number of respondents used in the statistical analysis from 810 to $781^{1}$.

For our purposes, it was crucial to elicit information about the perception of the overall distribution, without implicitly or explicitly imposing a priori a specific inequality measure. To make this abstract concept more or less operational, we have chosen the income ruler method ${ }^{2}$. The respondents were confronted with twelve double measuring rods, each for a different occupation. Acquaintance of the respondents with the occupations was important. They have therefore been chosen from six important sectors of the economy. Each sector is represented by two occupations: a lower and a higher one on the hierarchical scale. The twelve occupations are listed in Table 1. For each of these occupations the respondent was asked to indicate on the left measuring rod his estimate of the monthly net income of a middle-aged (about 40 years old) practitioner of that occupation. On the right measuring rod the respondent indicated the income he considered as fair for that occupation. A thirteenth double measuring rod was added on which the respondents had to give the same information about their own income position.

\footnotetext{
${ }^{1}$ Flanders is the (richer) northern part of Belgium. More detailed information on the survey can be found in Bouckaert et al. (1990). Some results from the second part on distributive justice have been described in Schokkaert and Capéau (1991).

${ }^{2}$ This method has already been used in other work. See, e.g., Overlaet and Lagrou (1981), Schokkaert and Lagrou (1983) for Belgium; Arts, Hermkens and van Wijck (1991), van Wijck (1994) for the Netherlands; Taylor-Gooby (1993) for the international comparison study of the ISSP.
} 
Table 1. The twelve occupations

\begin{tabular}{lll}
\hline Sector & Higher occupation & Lower occupation \\
\hline Medical care & General practitioner & Nurse \\
Education & Professor & Teacher primary school \\
Construction & Building contractor & Bricklayer \\
Industry & Head of department & Blue-collar worker \\
Public sector & Head of department & Typist \\
Distribution & Director department store & Grocer \\
\hline
\end{tabular}

A first insight into these data is given by Table 2, which shows the average perceived and fair incomes for the twelve occupations in Belgian francs per month. On average the respondents advocate substantial transfers from the top to the bottom income positions. At the same time, the ranking of the occupations with respect to income level does not change drastically. A detailed analysis of the interindividual variation in these data for the twelve occupations would lead us directly into the domain of distributive justice and the adequate compensation for job characteristics. This is not the main purpose of this paper, in which we will use the information on the occupations as raw material to construct the perception and evaluation of the overall distribution by our respondents.

Table 2. The average perceived and fair distribution

\begin{tabular}{lcccccc}
\hline Occupation & Perceived & rank & Fair & rank & Transfer & Weight \\
\hline Practitioner & 107654 & 1 & 94971 & 1 & -12683 & .009244 \\
Building contractor & 98268 & 2 & 90104 & 2 & -8164 & .010410 \\
Professor & 94271 & 3 & 82871 & 3 & -11401 & .008890 \\
Director Dep. Store & 81236 & 4 & 73882 & 4 & -7353 & .020045 \\
Head Dep. (Publ.) & 58380 & 5 & 54506 & 6 & -3875 & .086224 \\
Head Dep. (Indust.) & 57341 & 6 & 57315 & 5 & -26 & .025868 \\
Grocer & 49319 & 7 & 51734 & 7 & +2415 & .154241 \\
Bricklayer & 38556 & 8 & 42456 & 9 & +3900 & .035386 \\
Teacher & 37817 & 9 & 42077 & 10 & +4260 & .051527 \\
Nurse & 37348 & 10 & 45015 & 8 & +7667 & .019655 \\
Typist & 35353 & 11 & 38976 & 12 & +3622 & .170636 \\
Blue-collar worker & 34545 & 12 & 39114 & 11 & +4569 & .407774 \\
\hline
\end{tabular}

To construct a picture of the overall income distribution from the answers on the income ruler, we have to take into account the number of people in the various occupations. The perception of these numbers may differ among the 
respondents but we have no information in this regard. We therefore used a set of objective weights for the proportions of people in the different occupations, based on the Social Economic Inquiry of the Belgian National Institute for Statistics in $1977^{3}$. These weights are shown in the last column of Table 2 . Their relevancy is illustrated in Table 3. The first two columns of that table show the results of a double averaging process. To get the first column, we calculated in a first stage for each respondent the simple average of the twelve perceived incomes, the twelve fair incomes and the twelve absolute changes in incomes. In a second stage we averaged these figures over all 781 respondents. For the second column we have computed in the first stage weighted averages for each individual respondent. The differences are striking (and can be explained easily by the fact that the Belgian economy contains more active people in the lower income than in the higher income occupations from our questionnaire). An interesting check on our procedure is given in the third column, which gives the average of the own reported incomes of the respondents. If the average perception of the actual distribution is more or less realistic and if the respondents report their own income sincerely this number in the third column should be close to the first number in the second column. It is. Although the system of weights has to be taken with a grain of salt, this result increases our confidence in the procedure. Anyway, the complete neglect of the weights would be completely unacceptable. All our calculations of inequality measures in the following sections will therefore be based on the weighted data.

Table 3. Characteristics of the weighted and unweighted income distribution

\begin{tabular}{lccc}
\hline & unweighted & weighted & own income \\
\hline perception of average & 60841 & 42781 & 42566 \\
fair average & 59418 & 45357 & \\
average absolute change & -1422 & +2576 & \\
\hline
\end{tabular}

\section{Dominance results: a preliminary exercise}

Let us first, by way of introduction, investigate whether it is possible to derive from the answers some idea about what inequality measure is implicitly used by the respondents. Indeed, if one accepts the hypothesis that respondents prefer their own "fair" income distribution $y_{f}$ over their "perceived" actual distribution

\footnotetext{
${ }^{3}$ This Social Economic Inquiry was the closest possible to the period of the interviews.
} 
$y_{a}$, it follows that they reject through their answers those theoretical approaches according to which $y_{a}$ is better than $y_{f}$ from a social welfare point of view. If we were able to reject in that way a large subset of inequality measures for an individual respondent, we could build up a reasonable idea of the kind of measure he is implicitly using.

Table 4 shows that this idea does not bring us very far. For almost $20 \%$ of the respondents the fair distribution Pareto-dominates or first-degree stochastically dominates the perceived actual distribution. This implies of course that for these respondents $y_{f}$ is better than $y_{a}$ for all Paretian and symmetric social welfare functions. In $64.8 \%$ of the answers $y_{f}$ Lorenz-dominates $y_{a}$, and in $68.9 \%$ there is third-degree stochastic dominance. Since the average incomes in the fair and the perceived distribution are not necessarily equal, it is probably better to look at generalised Lorenz-dominance (Shorrocks, 1983): in almost 80\% of the answers we find generalised Lorenz-dominance of the fair distribution. Again, this implies that people's attitudes can be rationally justified by a very large range of social welfare functions and related inequality measures. This approach therefore does not yield very much information about the inequality measure used.

Table 4. Dominance results

\begin{tabular}{|c|c|c|c|}
\hline $\begin{array}{l}\text { Assumptions about underlying } \\
\text { social welfare function }\end{array}$ & $\mathrm{y}_{f}$ dominates $\mathrm{y}_{a}$ & $\mathrm{y}_{a}$ dominates $\mathrm{y}_{f}$ & no dominance \\
\hline Paretian & $17.4 \%$ & $0.0 \%$ & $82.6 \%$ \\
\hline $\begin{array}{l}\text { 2. } \mathrm{W}_{1} \quad \text { Paretian, Symmetric } \\
\text { (First Degree Stochastic Dominance) }\end{array}$ & $18.6 \%$ & $0.0 \%$ & $81.4 \%$ \\
\hline $\begin{array}{c}\text { 3. } \mathrm{W}_{2} \quad \text { Paretian, Symmetric, } \\
\text { S-concave }\end{array}$ & & & \\
\hline (Second Degree Stochastic Dominance) & $64.8 \%$ & $0.8 \%$ & $34.4 \%$ \\
\hline $\begin{array}{l}\text { 4. } \mathrm{W}_{3} \text { Paretian, Symmetric, } \\
\text { S-concave, Transfer sensitive }\end{array}$ & & & \\
\hline (Third Degree Stochastic Dominance) & $68.9 \%$ & $2.4 \%$ & $28.7 \%$ \\
\hline Generalised Lorenz Dominance & $79.8 \%$ & $1.4 \%$ & $18.8 \%$ \\
\hline
\end{tabular}

There is also a negative way of reading the same results by looking at them from the opposite angle. If $y_{a}$ dominates $y_{f}$ this can be seen as a rejection of the value judgments implied by that specific dominance relation. It turns out that this test is very weak indeed. None of our respondents reveals through his answers that he rejects the Pareto-principle or the symmetry-axiom. Only about $1 \%$ 
of the respondents can be shown to reject the Pigou-Dalton transfer principle (in that $y_{f}$, which we interpret as the "preferred" distribution is (generalised) Lorenzdominated by the perceived distribution). This contradicts sharply with the large percentage of students rejecting the transfer principle in the structured questionnaire studies (Amiel and Cowell, 1999). Only 2.4\% rejects transfer-sensitivity.

In table 5 we report some results for specific social welfare functions. The first column gives the proportion of respondents according to which the fair distribution leads to a lower level of welfare than the actual distribution for different values of the parameter of inequality aversion $\epsilon$ in the Atkinson (1970)-social welfare function:

$$
W_{A}=\left[\sum_{i} w_{i} y_{i}^{1-\epsilon}\right]^{\frac{1}{1-\epsilon}}
$$

where $w_{i}$ is the weight assigned to occupation $i$. The second column gives the same information for different values of the inequality aversion in Kolm(1976)'s leftist social welfare function:

$$
W_{K}=\mu-\frac{1}{\alpha} \log \left[\sum_{i} w_{i} e^{\alpha\left(\mu-y_{i}\right)}\right]
$$

where $\mu$ is average income. Since the elasticity of marginal utility of income for this function is equal to $-\alpha y_{i}$ we make both columns comparable by showing the results for $\alpha=\epsilon / \mu$. Following the same idea as before we can say that about $15 \%$ of the respondents reject these social welfare functions at a low level of the degree of inequality aversion. At the same time, the differences between both columns are minor.

Table 5. Welfare comparisons for the Atkinson - and Kolm - measures

\begin{tabular}{llll}
\hline \multicolumn{3}{c}{$\mathrm{W}\left(\mathrm{y}_{f}\right)<\mathrm{W}\left(\mathrm{y}_{a}\right)$} \\
\hline$\epsilon$ & Atkinson & Kolm \\
\hline 0 & & $\left.\alpha=\frac{\epsilon}{\mu}\right)$ & \\
0.2 & $17 \%$ & 0 & $17 \%$ \\
0.5 & $15 \%$ & 0.2 & $15 \%$ \\
1 & $12 \%$ & 0.5 & $12 \%$ \\
1.5 & $11 \%$ & 1 & $10 \%$ \\
3 & $9 \%$ & 1.5 & $9 \%$ \\
5 & $7 \%$ & 3 & $7 \%$ \\
10 & $7 \%$ & 5 & $7 \%$ \\
\hline
\end{tabular}


We can summarize: without further explicit questions -something which is exceptional in survey research with large samples- it is not possible to derive very specific information on the inequality measure implicitly used by the respondents. To analyse these answers, the researcher cannot avoid making his own choice of inequality measure. Let us therefore now turn to the main topic of this paper: the sensitivity of the findings with respect to this (more or less arbitrary) choice.

\section{A global analysis of perceived and desired inequality}

In the introduction we have mentioned two important questions in empirical research on justice opinions. The first relates to the perception of the actual income distribution, the second to the desired changes in income inequality. A summary overview of some of our empirical results is given in table 6 , showing the average values of different inequality measures, both for the perceived and the fair distribution. The inequality in the former is represented by $I\left(y_{a}\right)$, in the latter by $I\left(y_{f}\right)$. The inequality measures used are the range $\mathrm{R}$, the relative mean deviation $\mathrm{RMD}$, the coefficient of variation $\mathrm{CV}$, the standard deviation of the logs SDL, the Gini-coefficient G, Atkinson's inequality measure A for different values of $\epsilon$, indicated by the subscript, Kolm's leftist measure K for different values of $\alpha=\epsilon / \mu$, with the subscript indicating the relevant value of $\epsilon$, and finally the generalised entropy measure $\mathrm{C}$ with parameter $\gamma$, indicated in the subscript. It is well known that $\mathrm{C}_{0}$ is the Theil-coefficient, that $\mathrm{C}_{1}=\frac{\mathrm{CV}^{2}}{2}$, and that for negative values of $\gamma$, the measure $\mathrm{C}$ is ordinally equivalent to the measure $\mathrm{A}$ if $\gamma=-\epsilon$. 
Table 6. Average inequality : perceived and fair

\begin{tabular}{ccccc}
\hline Measure & $I\left(y_{a}\right)$ & variance $I\left(y_{a}\right)$ & $I\left(y_{f}\right)$ & variance $I\left(y_{f}\right)$ \\
\hline $\mathrm{R}$ & 2.2345 & 1.2083 & 1.6340 & .9620 \\
$\mathrm{RMD}$ & .2638 & .1058 & .1989 & .0914 \\
$\mathrm{CV}$ & .3957 & .1655 & .2932 & .1351 \\
$\mathrm{SDL}$ & .3029 & .1041 & .2357 & .0916 \\
$\mathrm{G}$ & .1652 & .0609 & .1251 & .0535 \\
& & & & \\
$\mathrm{~A}_{0.5}$ & .0310 & .0222 & .0189 & .0153 \\
$\mathrm{~A}_{1}$ & .0560 & .0380 & .0348 & .0270 \\
$\mathrm{~A}_{1.5}$ & .0762 & .0492 & .0483 & .0362 \\
$\mathrm{~A}_{2}$ & .0929 & .0574 & .0599 & .0434 \\
& & & & \\
$\mathrm{~K}_{0.5}$ & 1.6737 & 1.6970 & 1.1174 & 1.2790 \\
$\mathrm{~K}_{1}$ & 2.7784 & 2.5641 & 1.9168 & 2.0346 \\
$\mathrm{~K}_{1.5}$ & 3.5916 & 3.1070 & 2.5357 & 2.5402 \\
$\mathrm{~K}_{2}$ & 4.2283 & 3.4792 & 3.0381 & 2.9031 \\
& & & & \\
$\mathrm{C}_{-2}$ & .0537 & .0394 & .0331 & .0268 \\
$\mathrm{C}_{-1}$ & .0585 & .0418 & .0359 & .0287 \\
$\mathrm{C}_{0}$ & .0691 & .0521 & .0414 & .0349 \\
$\mathrm{C}_{+1}$ & .0920 & .0840 & .0521 & .0539 \\
$\mathrm{C}_{+2}$ & .1466 & .2125 & .0759 & .1409 \\
\hline & & & &
\end{tabular}

Two results are immediately clear. On average, there is a substantial reduction in inequality in going from the actual to the fair distribution. At the same time the interindividual variation in perceptions and opinions, as represented by the variance, is quite large. Let us now turn to a more detailed investigation of these interindividual differences.

\subsection{The perception of the actual distribution}

When we want to understand the interindividual variation in the perception of the income distribution, we are first interested to know who perceives the largest degree of inequality. In a later stage, we can try to go further and explain the differences in terms of the characteristics of the individual respondents. Let us investigate whether the choice of inequality measure matters for these two exercises. 
Who perceives the largest degree of inequality? To avoid using the cardinal properties of the different measures, we first rank all the respondents according to their individual value of $I\left(y_{a}\right)$ and then compute Spearman rank correlation coefficients between the ordered population vectors for different inequality measures. Table 7 shows that these correlations are remarkably high. At the same time, it illustrates in an attractive way the different features of the various inequality measures. As could be expected, the smallest correlations are found with the extremely crude measure of the range $(\mathrm{R})$, but even here the lowest correlation is .60. The perfect correlations between $\mathrm{C}_{1}$ and $\mathrm{CV}$, between $\mathrm{C}_{-1}$ and $\mathrm{A}_{1}$, and between $\mathrm{C}_{-2}$ and $\mathrm{A}_{2}$ have been theoretically predicted. The leftist Kolm-measure (which is not scale invariant) has in general lower correlations with the other measures than $\mathrm{A}$ or $\mathrm{C}$. Increasing inequality aversion (be it in A, $\mathrm{K}$, or $\mathrm{C}$ ) leads to decreasing correlations with CV - something which could be expected since CV does not satisfy transfer sensitivity. The reverse picture is found with SDL. The Gini and CV produce a quite different ordering, but G and SDL correlate quite well. $\mathrm{G}$ correlates best with $\mathrm{A}_{2}$ (and hence also with $\mathrm{C}_{-2}$ ). Within a parameterized measure the correlations are high for different values of the parameter, except for the C-measure with $\gamma$ exceeding zero. The correlations of RMD (which does not satisfy Pigou-Dalton) with the so-called better measures is remarkable. 


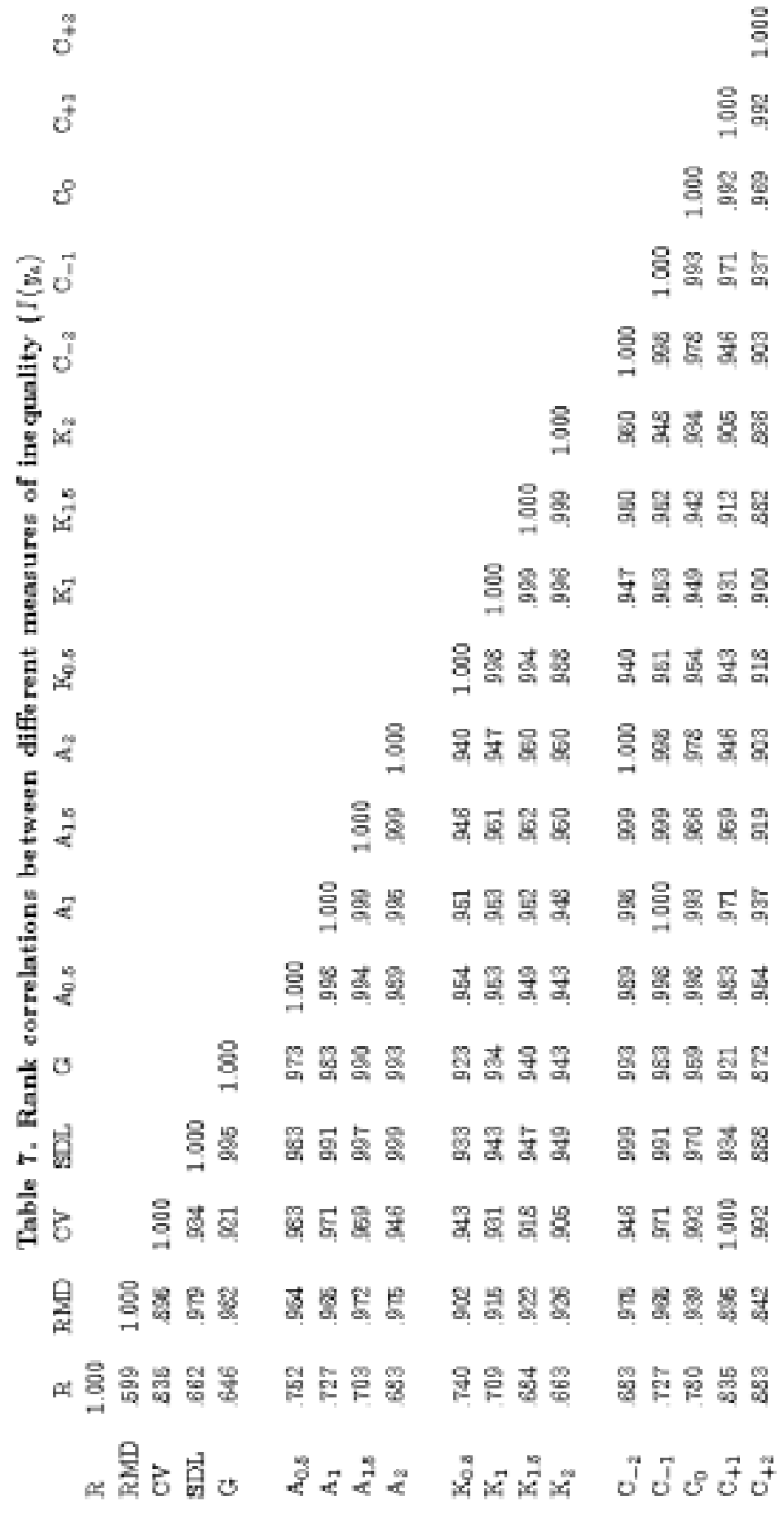


The overall message is clear: the choice of inequality measure does not matter too much for the ranking of respondents on the basis of their perception of overall income inequality. Let us therefore now go one step further and look at an explanation of the interindividual variation in terms of the socioeconomic characteristics of the respondents. The results of a traditional analysis for a selection of measures is given in the first column of the tables $8 \mathrm{a}-8 \mathrm{~g}$. These tables give the results of regressing $I\left(y_{a}\right)$ on the own income of the respondents, their age, their education level (the reference being the secondary school level), and their occupation (the reference is unskilled labourer, occupations 1, 2 and 3 refer to skilled labour, white-collar and executives/ professions respectively). Standard errors are between brackets and significant results (5\% significance level) are bold-faced.

Table 8. Explanation of perceived and fair inequality and of the tendency to equalize

Table 8a. Results for the range

\begin{tabular}{|c|c|c|c|c|c|c|}
\hline VARIABLE & \multicolumn{2}{|c|}{$I\left(y_{a}\right)$} & \multicolumn{2}{|c|}{$I\left(y_{f}\right)$} & \multicolumn{2}{|c|}{$\triangle I$} \\
\hline Constant & 1.2870 & $(.2447)$ & .9690 & $(.1951)$ & -25.0317 & $(4.5780)$ \\
\hline Own income & .0052 & $(.0028)$ & .0072 & $(.0023)$ & .1456 & $(.0532)$ \\
\hline Age & .0204 & $(.0047)$ & .0112 & (.0038) & -.1257 & $(.0884)$ \\
\hline Low education & -.1602 & $(.1143)$ & -.1530 & $(.0912)$ & -.6579 & $(2.1390)$ \\
\hline High education & -.1677 & $(.1152)$ & -.1804 & (.0919) & -2.3108 & $(2.1554)$ \\
\hline Female & -.0267 & $(.1012)$ & .0100 & $(.0807)$ & 1.8534 & $(1.8934)$ \\
\hline Occupation 1 & .0537 & $(.1569)$ & .0975 & $(.1251)$ & 1.2440 & $(2.9363)$ \\
\hline Occupation 2 & 1476 & $(.1558)$ & .0159 & $(.1242)$ & -2.9049 & $(2.9153)$ \\
\hline Occupation 3 & 1230 & (.1793) & 1320 & $(.1430)$ & 1.6373 & $(3.3551)$ \\
\hline $\mathrm{R}^{2}$, S.E.(\%) & .0500 , & .5321 & .0549, & .5787 & .0248, & .9175 \\
\hline \multicolumn{7}{|c|}{ Table 8b. Results for the Gini - coefficient } \\
\hline VARIABLE & \multicolumn{2}{|c|}{$I\left(y_{a}\right)$} & \multicolumn{2}{|c|}{$I\left(y_{f}\right)$} & \multicolumn{2}{|c|}{$\triangle I$} \\
\hline Constant & .1523 & $(.0125)$ & .0982 & $(.0110)$ & -32.4341 & $(4.0432)$ \\
\hline Own income & .0003 & $(.0001)$ & 0004 & $(.0001)$ & .1220 & $(.0470)$ \\
\hline Age & .0005 & $(.0002)$ & 0005 & $(.0002)$ & .0343 & $(.0781)$ \\
\hline Low education & -.0035 & $(.0059)$ & -.0013 & $(.0051)$ & 1.3703 & $(1.8891)$ \\
\hline High education & -.0081 & $(.0059)$ & -.0064 & $(.0052)$ & -.8016 & $(1.9036)$ \\
\hline Female & .0071 & $(.0052)$ & .0082 & $(.0045)$ & .7781 & $(1.6722)$ \\
\hline Occupation 1 & -.0139 & $(.0080)$ & -.0097 & $(.0070)$ & 8010 & $(2.5933)$ \\
\hline Occupation 2 & -.0210 & $(.0080)$ & -.0144 & $(.0070)$ & 1.7408 & $(2.5747)$ \\
\hline Occupation 3 & -.0185 & (.0092) & -.0081 & $(.0080)$ & 5.1595 & $(2.9632)$ \\
\hline $\mathrm{R}^{2}$, S.E.(\%) & .0279, & .3680 & .0436 & .4243 & .0295 & .8407 \\
\hline
\end{tabular}


Table 8c. Results for $\mathbf{A}_{0.5}$

\begin{tabular}{|c|c|c|c|c|c|c|}
\hline VARIABLE & \multicolumn{2}{|c|}{$I\left(y_{a}\right)$} & \multicolumn{2}{|c|}{$I\left(y_{f}\right)$} & \multicolumn{2}{|c|}{$\triangle I$} \\
\hline Constant & .0277 & $(.0046)$ & .0126 & $(.0032)$ & -50.1257 & $(5.5603)$ \\
\hline Own income & .0001 & $(.0001)$ & 0001 & $(.0000)$ & .2170 & $(.0646)$ \\
\hline Age & .0002 & $(.0001)$ & 0001 & $(.0001)$ & .0085 & $(.1074)$ \\
\hline Low education & -.0012 & $(.0021)$ & -.0005 & $(.0015)$ & 2.3139 & $(2.5980)$ \\
\hline High education & -.0027 & $(.0022)$ & -.0020 & $(.0015)$ & -1.0162 & $(2.6179)$ \\
\hline Female & .0008 & $(.0019)$ & .0012 & $(.0013)$ & 1.5389 & $(2.2996)$ \\
\hline Occupation 1 & -.0041 & $(.0029)$ & -.0020 & $(.0020)$ & 2.0360 & $(3.5664)$ \\
\hline Occupation 2 & -.0073 & $(.0029)$ & -.0039 & $(.0020)$ & 2.6720 & $(3.5408)$ \\
\hline Occupation 3 & -.0066 & $(.0034)$ & -.0025 & $(.0023)$ & 7.0781 & $(4.0751)$ \\
\hline $\mathrm{R}^{2}$, S.E.(\%) & .0240 & .7139 & .0350 & .8007 & .0362 & .7439 \\
\hline \multicolumn{7}{|c|}{ Table 8d. Results for $A_{2}$} \\
\hline VARIABLE & \multicolumn{2}{|c|}{$I\left(y_{a}\right)$} & \multicolumn{2}{|c|}{$I\left(y_{f}\right)$} & \multicolumn{2}{|c|}{$\triangle I$} \\
\hline Constant & .0845 & $(.0118)$ & .0407 & $(.0089)$ & -47.3099 & $(5.5596)$ \\
\hline Own income & .0002 & $(.0001)$ & .0003 & $(.0001)$ & .1991 & $(.0646)$ \\
\hline Age & .0005 & $(.0002)$ & 0004 & $(.0002)$ & .0408 & $(.1074)$ \\
\hline Low education & -.0030 & $(.0055)$ & -.0006 & $(.0041)$ & 2.3158 & $(2.5976)$ \\
\hline High education & -.0078 & $(.0056)$ & -.0054 & $(.0042)$ & -1.0775 & $(2.6176)$ \\
\hline Female & .0048 & $(.0049)$ & .0051 & $(.0037)$ & 1.3057 & $(2.2993)$ \\
\hline Occupation 1 & -.0134 & $(.0076)$ & -.0078 & $(.0057)$ & 1.1978 & $(3.5659)$ \\
\hline Occupation 2 & -.0210 & $(.0075)$ & -.0124 & $(.0057)$ & 2.0964 & $(3.5404)$ \\
\hline Occupation 3 & -.0192 & $(.0087)$ & -.0087 & $(.0065)$ & 6.5664 & $(4.0745)$ \\
\hline $\mathrm{R}^{2}$, S.E.(\%) & .0278 & .6164 & .0398, & .7178 & .0337 & .8010 \\
\hline \multicolumn{7}{|c|}{ Table 8e. Results for $K_{0.5}$} \\
\hline VARIABLE & \multicolumn{2}{|c|}{$I\left(y_{a}\right)$} & \multicolumn{2}{|c|}{$I\left(y_{f}\right)$} & \multicolumn{2}{|c|}{$\triangle I$} \\
\hline Constant & .9541 & $(.3485)$ & .3235 & $(.2622)$ & -47.3893 & $(6.6089)$ \\
\hline Own income & 0138 & $(.0040)$ & 0121 & $(.0030)$ & .2376 & $(.0768)$ \\
\hline Age & .0146 & $(.0067)$ & 0123 & $(.0051)$ & .0684 & $(.1276)$ \\
\hline Low education & -.0015 & $(.1628)$ & .0535 & $(.1225)$ & 3.1385 & $(3.0879)$ \\
\hline High education & -.1878 & $(.1641)$ & -.1389 & $(.1234)$ & -2.0625 & (3.1117) \\
\hline Female & .1478 & $(.1441)$ & .1593 & $(.1084)$ & 3.0777 & (2.7333) \\
\hline Occupation 1 & -.1619 & $(.2235)$ & -.0936 & $(.1682)$ & 1.5712 & $(4.2390)$ \\
\hline Occupation 2 & -.5246 & $(.2219)$ & -.2888 & $(.1669)$ & 3.3106 & $(4.2086)$ \\
\hline Occupation 3 & -.5489 & $(.2554)$ & -.2166 & $(.1921)$ & 9.4661 & $(4.8436)$ \\
\hline $\mathrm{R}^{2}$, S.E.(\%) & .0388 & 1.0041 & .0477, & 1.1299 & .0383 & 1.0960 \\
\hline
\end{tabular}


Table 8 f. Results for $\mathbf{K}_{\mathbf{2}}$

\begin{tabular}{|c|c|c|c|c|c|c|}
\hline VARIABLE & \multicolumn{2}{|c|}{$I\left(y_{a}\right)$} & \multicolumn{2}{|c|}{$I\left(y_{f}\right)$} & \multicolumn{2}{|c|}{$\triangle I$} \\
\hline Constant & 2.7652 & $(.7124)$ & 1.1576 & $(.5911)$ & -44.0616 & $(6.2615)$ \\
\hline Own income & .0311 & $(.0083)$ & 0299 & $(.0069)$ & .2155 & $(.0727)$ \\
\hline Age & .0268 & $(.0138)$ & 0278 & $(.0114)$ & .1291 & $(.1209)$ \\
\hline Low education & .0568 & $(.3329)$ & .1852 & $(.2762)$ & 2.8854 & $(2.9256)$ \\
\hline High education & -.4659 & $(.3354)$ & -.3263 & $(.2783)$ & -1.8190 & $(2.9481)$ \\
\hline Female & .3785 & $(.2947)$ & .4460 & $(.2445)$ & 2.6453 & $(2.5896)$ \\
\hline Occupation 1 & -.4352 & $(.4570)$ & -.3604 & $(.3791)$ & .0394 & $(4.0162)$ \\
\hline Occupation 2 & -1.1087 & $(.4537)$ & -.7283 & $(.3764)$ & 2.1516 & $(3.9874)$ \\
\hline Occupation 3 & -1.1421 & $(.5221)$ & -.5579 & $(.4332)$ & 8.1187 & $(4.5890)$ \\
\hline $\mathrm{R}^{2}$, S.E.(\%) & .0424 & .8134 & .0551 , & .9403 & .0404, & 1.1699 \\
\hline \multicolumn{7}{|c|}{ Table 8g. Results for $\mathrm{C}_{0}$ (Theil) } \\
\hline VARIABLE & \multicolumn{2}{|c|}{$I\left(y_{a}\right)$} & \multicolumn{2}{|c|}{$I\left(y_{f}\right)$} & \multicolumn{2}{|c|}{$\triangle I$} \\
\hline Constant & .0597 & $(.0108)$ & .0269 & $(.0072)$ & -50.8541 & $(5.5830)$ \\
\hline Own income & .0002 & $(.0001)$ & 0002 & $(.0001)$ & .2229 & $(.0648)$ \\
\hline Age & .0004 & $(.0002)$ & .0003 & $(.0001)$ & -.0070 & $(.1078)$ \\
\hline Low education & -.0030 & $(.0050)$ & -.0014 & $(.0034)$ & 2.3337 & $(2.6085)$ \\
\hline High education & -.0059 & $(.0051)$ & -.0045 & $(.0034)$ & -.9601 & $(2.6286)$ \\
\hline Female & .0014 & $(.0045)$ & .0021 & $(.0030)$ & 1.6610 & $(2.3090)$ \\
\hline Occupation 1 & -.0082 & $(.0069)$ & -.0036 & $(.0046)$ & 2.3717 & (3.5809) \\
\hline Occupation 2 & -.0158 & $(.0069)$ & -.0082 & $(.0046)$ & 2.7208 & $(3.5553)$ \\
\hline Occupation 3 & -.0145 & $(.0079)$ & -.0049 & $(.0053)$ & 7.1749 & $(4.0917)$ \\
\hline $\mathrm{R}^{2}$, S.E.(\%) & .0228, & .7530 & .0334 & .8382 & .0366 & .7297 \\
\hline
\end{tabular}

It is obvious that the explanatory power of the socioeconomic variables is very low. Yet the basic picture in table 8 is clear and, although there are some differences in the significance of the coefficients, basically the same for all measures ${ }^{4}$. Again, the results for the range differ most. Ceteris paribus older people perceive a larger degree of inequality in the income distribution. The same is true for respondents with a larger income, but this effect is less significant. White-collar workers and executives have (keeping age and income constant) a lower perceived inequality. These findings are interesting but in the light of the literature not very surprising $^{5}$. More important for the purpose of this paper is again the reassuring finding that the picture is extremely similar for the different inequality measures.

\footnotetext{
${ }^{4}$ Needless to say that the magnitude of the coefficients cannot be meaningfully compared, because of the different scaling of the dependent variable.

${ }^{5}$ See Arts and van der Veen (1992) for an overview of the sociological literature.
} 


\subsection{The tendency to equalize}

The second question relates to the ideas about the fair (re)distribution. The general overview has already been given in table 6 . When we rank the individuals according to their value of $I\left(y_{f}\right)$, the resulting matrix of rank correlations is very similar to the one given in table 7 and does not add much information. Let us therefore immediately turn to the explanation of these differences: the regression results are given in the second column of tables 8a-8g. There is some very weak evidence that white-collars prefer a more equal distribution than the others. There are two much stronger effects, however: older respondents and higher income-earners want more inequality in the fair distribution. While this pattern is somewhat different from that for the perceived inequality, again it turns out that the choice of inequality measure is not crucial for the exercise.

Finally, we combine the information about the perceived and the fair distribution. A traditional procedure is the computation of the percentage change in the inequality measure ${ }^{6}$, defined as $\triangle I=100\left[I\left(y_{f}\right)-I\left(y_{a}\right)\right] / I\left(y_{a}\right)$. The explanation of these changes is given in the last column of tables 8 . Given our definition, a reduction of inequality leads to a negative value of $\triangle I$ : a positive sign for a coefficient therefore means that this variable leads to a lower reduction of inequality. The results in the table are easily understood from the results described before. Since income has a strong positive effect on fair inequality and a much weaker effect on perceived inequality, it has a positive effect on $\triangle I$, i.e., high-income respondents reduce the income inequality to a lesser degree. The opinions of older people reflect a higher inequality both in the perceived and in the fair distribution: there is therefore no significant effect on the percentage reduction in inequality. None of the other variables is significant. The different inequality measures yield broadly the same results.

\section{Redistributors and non-redistributors}

In the previous section we have shown the results of some traditional empirical analyses: ranking respondents according to their degree of perceived and fair inequality, explaining the interindividual variation in these variables on the basis of the socioeconomic characteristics of the individuals. For all these exercises the

\footnotetext{
${ }^{6}$ Applied to the Theil-coefficient, Szirmai (1988) calls this the "tendency to equalize". The same concept is also used by Arts et al. (1991).
} 
choice of inequality measure did not matter much (perhaps with the exception of the most crude one, the range, for which the results were somewhat divergent). This is reassuring for those social scientists who until now limited themselves to Gini- or Theil-coefficients. Yet this does not settle everything. In this section we look at a discrete classification of the individuals according to the criterion: do they or do they not decrease inequality in going from the perceived to the fair distribution? In the next section we will ask some questions about the relevancy of the so-called tendency to equalise $\triangle I$, which has been introduced in the previous section.

Table 9 shows the results of a classification of the 781 respondents in three groups: those who decrease, increase, or keep inequality unchanged. Three respondents do not want to change the distribution. The majority of course reduces inequality, but the fraction of the population which increases inequality is substantial. Moreover, this fraction is different for the different measures ${ }^{7}$. For A, K and $\mathrm{C}$ the number of reverse redistributors increases with the inequality aversion. This reveals that the measure becomes more stern about inequality. From this point of view one can also say that the measure of Kolm is by far the most severe measure, a result which could be expected on prior grounds.

\footnotetext{
${ }^{7}$ The results in table 9 , based on the computation of income inequality measures with the income ruler method, can be compared with the answers on the following simple question: "Do you want the income differences (a) to become smaller; (b) to remain the same; (c) to become larger". Only $3 \%$ of the respondents chose the third option and $15 \%$ the second.
} 
Table 9. A discrete classification of respondents

\begin{tabular}{ccccccc}
\hline Measure & \multicolumn{2}{c}{ decrease } & \multicolumn{2}{c}{ increase } & \multicolumn{2}{c}{$\begin{array}{c}\text { inequality } \\
\text { inequality }\end{array}$} \\
& \multicolumn{2}{c}{ inequality } & \multicolumn{2}{c}{ unchanged } \\
\hline $\mathrm{R}$ & 717 & $(91.81)$ & 61 & $(7.81)$ & 3 & $(.38)$ \\
$\mathrm{RMD}$ & 695 & $(88.99)$ & 83 & $(10.63)$ & 3 & $(.38)$ \\
$\mathrm{CV}$ & 725 & $(92.83)$ & 53 & $(6.79)$ & 3 & $(.38)$ \\
$\mathrm{SDL}$ & 706 & $(90.40)$ & 72 & $(9.22)$ & 3 & $(.38)$ \\
$\mathrm{G}$ & 703 & $(90.01)$ & 75 & $(9.60)$ & 3 & $(.38)$ \\
& & & & & & \\
$\mathrm{A}_{0.5}$ & 719 & $(92.06)$ & 59 & $(7.55)$ & 3 & $(.38)$ \\
$\mathrm{A}_{1}$ & 716 & $(91.68)$ & 62 & $(7.94)$ & 3 & $(.38)$ \\
$\mathrm{A}_{1.5}$ & 714 & $(91.42)$ & 64 & $(8.19)$ & 3 & $(.38)$ \\
$\mathrm{A}_{2}$ & 706 & $(90.40)$ & 72 & $(9.22)$ & 3 & $(.38)$ \\
& & & & & & \\
$\mathrm{K}_{0.5}$ & 679 & $(86.94)$ & 99 & $(12.68)$ & 3 & $(.38)$ \\
$\mathrm{K}_{1}$ & 673 & $(86.17)$ & 105 & $(13.44)$ & 3 & $(.38)$ \\
$\mathrm{K}_{1.5}$ & 666 & $(85.28)$ & 112 & $(14.34)$ & 3 & $(.38)$ \\
$\mathrm{K}_{2}$ & 660 & $(84.51)$ & 118 & $(15.11)$ & 3 & $(.38)$ \\
& & & & & & \\
$\mathrm{C}_{-2}$ & 706 & $(90.40)$ & 72 & $(9.22)$ & 3 & $(.38)$ \\
$\mathrm{C}_{-1}$ & 716 & $(91.68)$ & 62 & $(7.94)$ & 3 & $(.38)$ \\
$\mathrm{C}_{0}$ & 720 & $(92.19)$ & 58 & $(7.43)$ & 3 & $(.38)$ \\
$\mathrm{C}_{+1}$ & 725 & $(92.83)$ & 53 & $(6.79)$ & 3 & $(.38)$ \\
$\mathrm{C}_{+2}$ & 725 & $(92.83)$ & 53 & $(6.79)$ & 3 & $(.38)$ \\
\hline & & & & & &
\end{tabular}

Another way to assess the equivalence between the measures is to count the number of conflicts. The first line of Table 10 presents the number of respondents for which all measures record a decrease in inequality, the number of respondents for which all measures record an increase in inequality, and the number of respondents for which there is at least one conflicting judgement. For $18.3 \%$ of the respondents there is at least one such conflict. This means that almost one fifth of the respondents are classified by one inequality measure as "willing to redistribute income" while the use of another inequality measure would lead to the conclusion that they in fact prefer more inequality. Since we have seen before that the range is somewhat out of line with the other measures, we omitted it from the exercise in the second line of the table: even then $13 \%$ of the respondents are classified differently by different measures. This result is somewhat worrying. In actual reality, politicians and citizens are not asked to reflect deeply and then give their 
preferred percentage reduction in inequality: the debate really is about the simple question whether or not inequality should be decreased. Nor is there much concern in everyday discussions about how this inequality should be measured. The results in Table 10 suggest that this may lead to confusion: if people are discussing these questions, they may be using (implicitly or explicitly) different measures, based on different assumptions ${ }^{8}$. It is therefore possible that apparent opponents in a heated debate in fact favour a very similar redistribution.

\begin{tabular}{lcccccc}
\multicolumn{7}{l}{ Table 10. Equivalences in the discrete classification by different } \\
inequality measures & & \\
\hline Subset of measures & \multicolumn{2}{c}{ decrease } & \multicolumn{2}{c}{ increase } & conflicting \\
& inequality & inequality & judgement \\
\hline All measures & 611 & $(78.23)$ & 23 & $(2.94)$ & 147 & $(18.28)$ \\
All measures, except R & 636 & $(81.43)$ & 42 & $(5.38)$ & 103 & $(13.19)$ \\
G, A, K, C $\forall \epsilon, \alpha, \gamma$ & 642 & $(82.20)$ & 43 & $(5.51)$ & 96 & $(12.29)$ \\
$\mathrm{A} \forall \epsilon$ & 706 & $(90.40)$ & 62 & $(7.94)$ & 13 & $(1.66)$ \\
$\mathrm{K} \forall \alpha$ & 654 & $(83.74)$ & 96 & $(12.29)$ & 31 & $(3.97)$ \\
$\mathrm{C} \forall \gamma$ & 697 & $(89.24)$ & 47 & $(6.02)$ & 37 & $(4.74)$ \\
$\mathrm{A}_{1.5}$ and $\mathrm{K}_{1.5}$ & 663 & $(84.89)$ & 64 & $(8.19)$ & 54 & $(6.91)$ \\
\hline
\end{tabular}

Some further results for subsets of inequality measures are shown further down Table 10. The influence of the inequality aversion parameter is found in lines 4,5, and 6 . Increasing the value of $\epsilon$ from 0 to 2 in the Atkinson-family produces only 13 conflicts. An analogous increase in the value of $\alpha$ in the Kolm-measures gives 31 conflicting judgements. The still larger number of conflicts for the generalized entropy measure may be due to the wider range over which $\gamma$ is increased (from -2 to +2 ). Yet, in general it is somewhat surprising how relatively unimportant is this variation in the parameter of inequality aversion. Another interesting comparison is the one between $A_{1.5}$ and $K_{1.5}$ : although the parameter of inequality aversion is the same (1.5), the number of respondents that are classified differently is rather large (almost 7\%). Remember that the Kolm-measures are not scale-invariant and start from the assumption that inequality increases if all incomes increase proportionally.

\footnotetext{
${ }^{8}$ Moreover, it may well be the case that the range, however crude for economist's standards, is actually dominating the perceptions of many respondents. In that case the first row of table 10 is the most relevant and we have to consider the possibility of $20 \%$ of conflicting judgments. Note, e.g., that the analysis in Taylor-Gooby (1993) and in Miller (1995) focuses exlusively on the range.
} 


\section{Tendency to equalize, conservatism and distributional change}

An important aspect in the social debate is the degree of conservatism of the citizens: how strongly do they keep to the existing income distribution? Very often, this conservatism is measured in terms of the desired change in any inequality measure, i.e. the tendency to equalize $(\triangle I)$ in section 4 . Yet these inequality measures are symmetric and it is well known that by concentrating exclusively on this aspect of the redistribution process, we may be missing some important aspects. The problem is illustrated in Table 11. Compare the distributions I and II in the table. Reordering the incomes, irrespective of the identity of the individuals, yields exactly the same vector. This implies that, according to any measure of vertical inequality, inequality has remained the same in going from I to II. But the example clearly shows that this does not mean that there have been no changes in the distribution: there obviously has been a revolutionary change. If we measure a so-called "tendency to equalise" this change is completely swept under the carpet, because the identity of the individuals does not matter in traditional vertical inequality measurement. Now compare divisions I and III: there has been a small rich-to-poor transfer and therefore inequality is smaller in III than in I for any inequality measure satisfying the Pigou-Dalton-criterion (and in this example also for the range). Therefore, the tendency to equalise will not be zero. Yet, it is obvious that the shift from I to III is a much less drastic one than the shift from I to II. In so far as we want to say something about conservatism, this aspect is not captured adequately by the concept of the tendency to equalise: we need a more direct measure of the "tendency to change the existing distribution".

Table 11. Change and redistribution

\begin{tabular}{lccc}
\hline Division & A & B & C \\
\hline I & 100 & 150 & 200 \\
II & 200 & 150 & 100 \\
III & 101 & 150 & 199 \\
\hline
\end{tabular}

Of course the theoretical literature contains many measures of horizontal inequality trying to take into account the identity of the individuals and often based on the concept of rank reversals. However, the idea of horizontal inequity goes somewhat further than the implicit notion of "amount of change". A more direct measure of this latter notion has been proposed by Cowell (1980). He develops 
a measure of "distributional change" as an extension of the generalized entropy measures of vertical inequality. The vertical inequality measures of the generalized entropy class are based on the formal analogy with the expected information content of a direct message in information theory. Pursuing the analogy with information theory, Cowell uses the expected informational content of an indirect message to define an inequality measure for the change in the distribution. The measure is defined on both the vectors $y_{a}$ and $y_{f}$ and on an inequality aversion parameter $\beta$ :

$$
D=\frac{1}{\beta(1+\beta)} \sum_{i} w_{i} \frac{y_{f}^{i}}{\mu_{f}}\left\{\left[\frac{\mu_{a}}{\mu_{f}} \frac{y_{f}^{i}}{y_{a}^{i}}\right] \beta-1\right\}
$$

where as before the subscripts a and $f$ refer to the actual and the fair distribution respectively and $\mu$ to the weighted average of the incomes.

The measure D has some interesting properties. If there is a non-proportional change in the income distribution the measure is always nonnegative, whether vertical inequality decreases or not. (This implies inter alia that it will be positive in the case of simple permutations, such as the shift from distribution I to II in Table 11). The effect of a simple income swap on the measure is greater, the greater is the ratio of the swapped incomes. A partial income equalisation leads to less distributional change than a complete equalisation. A direct swap between any two people with different incomes produces greater measured distributional change than income equalisation between them. As in the generalised entropy measures, the parameter $\beta$ reflects the sensitivity of the measure to income transfers. Without going in more details, it must be clear that this measure is better suited to measure the degree of conservatism than the "tendency to equalise"-concept(s).

Let us therefore look at the explanation of this measure of distributional change, as given in Table 12. New elements clearly appear. Age is no longer significant, and the significance of own income decreases considerably. There is also a slight effect of occupation; white collars and executives are somewhat more conservative. But a new variable now enters the picture: education. It appears that both lower and higher educated people induce a larger distributional change in going from the actual to the fair distribution, but the effect is only significant for the low education-variable. This pattern makes sense. Moreover, it is striking that it differs from the results in the last column of tables 8 . The measure really seems to capture another psychological reality. 
Table 12. Results for the measure of distributional change

\begin{tabular}{lcccccc}
\hline VARIABLE & \multicolumn{2}{c}{$\beta=-2$} & \multicolumn{2}{c}{$\beta=0$} & \multicolumn{2}{c}{$\beta=2$} \\
\hline Constant & $\mathbf{. 3 0 0 1}$ & $(.0463)$ & $\mathbf{. 3 2 2 7}$ & $(.0463)$ & $\mathbf{. 3 5 8 1}$ & $(.0522)$ \\
Own income & $\mathbf{- . 0 0 1 1}$ & $(.0005)$ & -.0010 & $(.0005)$ & -.0009 & $(.0006)$ \\
Age & -.0012 & $(.0009)$ & -.0012 & $(.0009)$ & -.0016 & $(.0010)$ \\
Low education & .0408 & $(.0216)$ & $\mathbf{. 0 4 5 5}$ & $(.0216)$ & $\mathbf{. 0 5 3 3}$ & $(.0244)$ \\
High education & .0385 & $(.0218)$ & .0366 & $(.0218)$ & .0379 & $(.0246)$ \\
Female & -.0216 & $(.0192)$ & -.0203 & $(.0191)$ & -.0194 & $(.0216)$ \\
Occupation 1 & -.0326 & $(.0297)$ & -.0296 & $(.0297)$ & -.0441 & $(.0335)$ \\
Occupation 2 & $\mathbf{- . 0 6 6 1}$ & $(.0295)$ & -.0493 & $(.0295)$ & -.0546 & $(.0332)$ \\
Occupation 3 & $\mathbf{- . 0 7 4 0}$ & $(.0339)$ & -.0600 & $(.0339)$ & -.0646 & $(.0382)$ \\
\hline $\mathrm{R}^{2}$, S.E. $\left.\%\right)$ & .0432, & 1.2788 & .0362, & 1.0479 & .0318, & 1.0686 \\
\hline
\end{tabular}

More research is needed to understand better the relationship between the tendency to equalise, conservatism and measures of distributional change. Moreover, there remains the open question of how to integrate the idea of horizontal equity in this measurement exercise. However, the simple analysis in this section suggests that it is necessary to distinguish carefully these different concepts. The crucial idea of conservatism is not captured adequately by the concept of the tendency to equalise. It is socially relevant to devise and use more refined measures.

\section{Conclusion}

Our starting point was the huge gap between the theoretical literature on inequality measurement and the empirical research on distributive judgments. There is no doubt that the concept of distributive justice figuring prominently in the social debate has to do with the degree of inequality in the income distribution and that value judgments are needed to get at a measure of this inequality. The degree of inequality definitely is not an objective concept. Much confusion can arise if one is simply talking about "more or less inequality" without making explicit these value judgments. Therefore there are good a priori reasons to suppose that the rather frivolous use of inequality measures in empirical research might be dangerous. With this paper we wanted to see how serious is this danger.

Our analysis is based on data from a representative sample of the Flemish working population. The respondents had to give their perception of the actual and fair income for twelve occupations. These answers were used to reconstruct their ideas about the overall income distribution (both perceived and fair). We 
then applied the apparatus of inequality measurement to these constructed income distributions.

To a certain extent, the message of this paper is reassuring. For many of the traditional empirical exercises the choice of inequality measure makes almost no difference. The ranking of individuals on the basis of their perceived and fair inequality is hardly affected. The explanation of interindividual variation in the answers remains almost the same, whatever the measure used. And the same is true for the tendency to equalise, operationalised as the percentage change in inequality when going from the actual to the fair distribution. Only with the range some caution is needed: this crude measure seems to behave differently from the others.

But things become less clear when we go somewhat deeper. First, in many cases we are not interested in a complete ranking of the individuals. What we need is a clear classification in those who want and those who do not want less inequality. The answers to this simple and straightforward question diverge for the different measures. There is room for confusion here. Moreover, the tendency to equalise is a very poor measure of the conservatism of the respondents: even revolutionary shifts in the income distribution are not recorded by vertical inequality measures. New insights are gained when we try to capture these considerations with Cowell (1980)'s measure of distributional change. Conservatism does not coincide necessarily with a low tendency to equalize and the socioeconomic correlates of both concepts are different.

The ambition of this paper is limited. It is only a very first step in trying to introduce more theoretical concepts from the literature on inequality measurement into the empirical research on distributive judgments. Our results suggest that

this introduction may be fruitful. We consider this exercise as complementary to the more carefully structured questionnaire studies as exemplified in the work of Amiel and Cowell (1999) and Harrison and Seidl (1994a, 1994b). The exploration of possible links is left for future research.

\section{References}

Amiel, Y., Cowell, F. (1999), Thinking about inequality (Cambridge: Cambridge University Press).

Arts, W., Hermkens, P., van Wijck, P. (1991), Income and the idea of justice: principles, judgments and their framing, Journal of Economic Psychology 12, 121140 . 
Arts, W., van der Veen, R. (1992), Sociological approaches to distributive and procedural justice, in K. Scherer (ed.), Justice: interdisciplinary perspectives (Cambridge: Cambridge University Press), 143-176.

Atkinson, A. (1970), On the measurement of inequality, Journal of Economic Theory 2, 244-263.

Ballano, C., Ruiz-Castillo, J. (1993), Searching by questionnaire for the meaning of income inequality, Revista Espanola de Economia 10, 233-259.

Bouckaert, L. et al. (1990), Wie verdient meer? (Leuven: Acco).

Cowell, F. (1980), Generalised entropy and the measurement of distributional change, European Economic Review 13, 147-159.

Harrison, E., Seidl, C. (1994a), Acceptance of distributional axioms: experimental findings, in W. Eichhorn (ed.), Models and measurement of welfare and inequality (Berlin: Springer), 67-99.

Harrison, E., Seidl, C. (1994b), Perceptional inequality and preferential judgments: an empirical examination of distributional axioms, Public Choice 79, 6181.

Kolm, S.-Chr. (1976), Unequal inequalities I, Journal of Economic Theory 12, 416-442.

Miller, D. (1995), Popular beliefs about social justice: a comparative approach, in S. Svallfors (ed.), In the eye of the beholder (Bank of Sweden Tercentenary Foundation), 71-103.

Overlaet, B., Lagrou, L. (1981), Attitude towards a redistribution of income, Journal of Economic Psychology 1, 197-215.

Schokkaert, E., Capéau, B. (1991), Interindividual differences in opinions about distributive justice, Kyklos 44, 325-345.

Schokkaert, E., Lagrou, L. (1993), An empirical approach to distributive justice, Journal of Public Economics 21, 33-52.

Shorrocks, A. (1983), Ranking income distributions, Economica 50, 3-17.

Szirmai, A. (1988), Inequality observed (Alderhof: Avebury/Gower).

Taylor-Gooby, P. (1993), What citizens want from the state, in R. Jowell et al., International Social Attitudes, the 10th BSA Report (Social and Community Planning Research, Dartmouth, Aldershot), 81-101. 
van Wijck, P. (1994), Evaluating income distributions, Journal of Economic Psychology 15, 173-190. 